\title{
Publisher's Note: Effects of high solenoidal magnetic fields on rf accelerating cavities [Phys. Rev. ST Accel. Beams 8, 072001 (2005)]
}

A. Moretti, Z. Qian, J. Norem, Y. Torun, D. Li, and M. Zisman

(Received 7 September 2005; published 9 September 2005)

DOI: 10.1103/PhysRevSTAB.8.099901

PACS numbers: 29.17.+w, 52.80.Vp, 73.22.-f, 99.10.Fg

This paper was published online on 6 July 2005 with a typographical error in Ref. [2]. Reference [2] should read as “M. Alsharo'a et al., Phys. Rev. ST Accel. Beams 6, 081001 (2003)." The reference has been corrected as of 7 September 2005. 